\title{
PRIVATE AND PUBLIC SELF-CONSCIOUSNESS SUBSCALES OF THE FENIGSTEIN, SCHEIER AND BUSS SELF-CONSCIOUSNESS SCALE: A TURKISH TRANSLATION
}

\author{
R. Neslihan Ruganc1 \\ Psychological Counseling and Research Center, Bilkent University, Ankara, Turkey
}

(Received 2I January 1994)

\begin{abstract}
Summary - The aim of the study was to analyze the psychometric properties of public and private subscales of the self-consciousness scale (Fenigstein, Scheier \& Buss, Journal of Consulting and Clinical Psychology, $43,522-527,1975$ ) on a sample of Turkish University students. Two pilot studies were carried out to explore the efficacy of the translated version. Then, in the main study, the final reliability and construct validity analysis were carried out on a sample of $\mathbf{2 5 3}$ students from various departments of Middle East Technical University. Results confirmed both the two factor structure of the private self-consciousness scale which had been reported by Bunkrant and Page (Journal of Personality Assessment, 48, 629-637, 1984), and Piliavin and Charng (Personality and Social Psychology Bulletin, 14,587-595, 1988) and the psychometric properties of the public self-consciousness scale which had been reported in the original study (Fenigstein et al., 1975). The Turkish version of each subscale is seemingly applicable on Turkish populations.
\end{abstract}

\section{INTRODUCTION}

Duval and Wicklund (1972) defined 'self-awareness' as a state experienced while attention is directed to self. In the empirical research, such a state was obtained as a result of the manipulation of certain transient situational variables such as a mirror, an audience, a tape recorder or a T.V. camera (Duval \& Wicklund, 1972, 1973; Ickes, Wicklund \& Ferris, 1973; Wicklund, 1975). Manipulating these instruments were shown to have different effects on self-awareness: whereas mirror manipulations heightened the $S$ 's attention to internal states or private aspects of self such as thoughts, feelings, motives; audience, T.V. camera, tape recorder manipulations were found to heighten the $S$ 's attention toward his/her public aspects of self, such as one's social and physical appearance (Baldwin \& Holmes, 1987; Carver \& Scheier, 1981; Franzoi \& Brewer, 1984; Froming, Walker \& Lopyan, 1982; Scheier \& Carver, 1977, 1980; Scheier, Buss \& Buss, 1978; Scheier, Carver \& Gibbons, 1979).

Fenigstein, Scheier and Buss (1975) emphasized an individual difference suggesting that one may have a dispositional tendency to maintain self-awareness which has been conceptualized as 'self-consciousness'. Like self-awareness, self-consciousness is conceived as having two dimensions: 'public' and 'private'. They devised an instrument to measure these two dimensions and 'social anxiety' which accounts for the degree of discomfort felt in the presence of others. Empirical research devoted to self-consciousness suggests that private and public self-consciousness are two independent dimensions that operate as important mediating variables. These exert similar effects as private and public self-awareness on different occasions, such as in the engagement of public or private self-consciousness during the day (Franzoi \& Brewer, 1984); in the correlation with social or personal identity (Cheek \& Briggs, 1982); in the correlation with 'suggestibility' (Scheier et al., 1979); in the exhibition of the 'reactance' effect (Carver \& Scheier, 1981); in the 'dissonance' phenomena (Davis, 1984; Scheier \& Carver, 1980); in self-schema articulation (Mueller, Thompson \& Dugan, 1986; Nasby, 1989, 1985; Turner, 1978a); in predictive validity of self-reports (Franzoi, 1983; Turner, 1978 b); in accessibility of 'physical attractiveness schema' (Turner, Gilliland \& Klein, 1981); in recall of self-reference tasks (Agatstein \& Buchanan, 1984).

The aim of this study was to examine the psychometric properties of private and public subscales of the self-consciousness scale on a sample of Turkish University students. Before the main study, two pilot studies were carried out to find the response tendencies of the population toward the translated subscales and to establish the efficacy of the translation. 


\section{PILOT STUDIES}

In the first pilot study 54 students from the Middle East Technical University (M.E.T.U.) completed the private and the public self-consciousness items of the self-consciousness scale. The sample consisted of 16 males and 34 females ( 4 Ss did not mention their sex) in the age range of 17-21 yr.

The private self-consciousness subscale ( $\mathrm{PrSC}$ ) and the public self-consciousness subscale ( $\mathrm{PbSC}$ ) of the self-consciousness scale (Fenigstein et. al., 1975) were translated into Turkish and applied. After 17 items (10 PrSC items and $7 \mathrm{PbSC}$ items) were translated into Turkish, some revisions on the translated versions were made and these were then backtranslated into English by bilingual experts. Backtranslation of the subscales were similar in meaning to the original American version. After omitting the social anxiety subscale items from the scale, the original order of items were kept.

Male and female $S$ s had a mean of $24.69(\mathrm{SD}= \pm 6.00)$ and $26.03(\mathrm{SD}= \pm 5.64)$ on the PrSC subscale, respectively, and $16.56(\mathrm{SD}= \pm 6.45), 19.21(\mathrm{SD}= \pm 4.86)$ on the PbSC subscale, respectively. The mean scores of male and female students showed no significant difference on either subscale. $\alpha$ coefficients of the PrSC and PbSC were found to be 0.64 and 0.80 , respectively. The correlation between two subscales were found to be 0.39 which was higher than the correlation obtained in the original study $[0.23$ for males, 0.26 for females (Fenigstein et al., 1975, p. 525)].

The criteria for weak items were set as having the item total correlation, and the squared multiple correlation, both, below 0.30. Two items in $\operatorname{PbSC}(2,21)$ and three items in $\operatorname{PrSC}(3,13,20)$ were identified to be weak.

Certain translation inefficacies may have contributed to the weakness of these items. Although, the backtranslation of the items appeared similar to the original versions, the semantic structure of the weak Turkish items were still loose compared to the rest of the items in the subscale, as they gave vague information about the meaning and were open to subjective evaluation of what the item was about. These problems can usually be solved in Turkish through adding supportive words to the sentence that help clarify the meaning. Therefore in the second pilot study, the identified weak items were subjected to revision without changing the original meaning, to improve the homogeneity, thus increasing the reliability of the subscales. The revised items and the original items were presented to two bilingual experts on separate lists. The items were mixed and the experts were asked to match similar items on the two separate lists, independent of each other. Matching was completed without error.

Achievement of more independent subscales was another objective of the second pilot study.

Sixty-one M.E.T.U students, 17 males and 40 females ( $4 \mathrm{Ss}$ did not mention their sex) in the age range of $17-19 \mathrm{yr}$, took part in the second pilot study.

Means and standard deviations of the PrSC and PbSC were calculated without analyzing sex difference since there had been no significant difference in the first pilot study $(X=27.04$, $\mathrm{SD}= \pm 5.20 ; X=17.66, \mathrm{SD}= \pm 5.58$, respectively) and the $\alpha$ coefficients of the subscales were obtained as $0.60,0.78$, respectively.

Although item 21 of the PbSC showed a slight improvement, it was still a weak item. The same item had also been reported to be weak by Bunkrant and Page (1984). However, item 2, which was revised, showed a reasonably high item total correlation and squared multiple correlation exceeding the limit set.

Items 7, 9 and 18 of the PrSC appeared weak. Item 3 could also be considered weak, since it exhibited almost no correlation with the total scale $(r / t: 0.05)$, although its squared multiple correlation exceeded the limit that was set for the weak item. Items 3, 9 (Bunkrant \& Page, 1984; Piliavin \& Charng, 1988) and item 7 (Piliavin \& Charng, 1988) had also been reported to be weak in previous studies. The weakness of item 18 could have stemmed from the perception of the content of the item in the Turkish culture as being mystical ("having the feeling that being off somewhere watching his/herself").

The correlation between the PrSC and PbSC was obtained as 0.36, exhibiting a 0.03 decrease compared to the first pilot study, but it was still higher than the correlation obtained in the original study. However, this amount approximated to the correlation between the PrSC and PbSC obtained in the various studies carried out on American samples: 0.39 (Cheek \& Briggs. 1982; Penner \& Wymer, 1983); 0.37 (Edelmann, 1985). 
Table 1. Factor loadings of the PrSC and PbSC items

\begin{tabular}{|c|c|c|c|c|}
\hline Items & $\begin{array}{l}\text { A priori scale } \\
\text { assignments }\end{array}$ & $\begin{array}{c}\text { Factor } 1 \\
\text { (PbSC) }\end{array}$ & $\begin{array}{c}\text { Factor } 2 \\
\text { (self- } \\
\text { reflectiveness) }\end{array}$ & $\begin{array}{l}\text { Factor } 3 \\
\text { (internal } \\
\text { state } \\
\text { awareness) }\end{array}$ \\
\hline$(1)^{*}$ & & & 0.63 & \\
\hline (2) & & 0.68 & & \\
\hline (5) & & & 0.44 & \\
\hline (6) & & 0.80 & & \\
\hline (11) & & 0.78 & & \\
\hline (13) & & & & -0.75 \\
\hline (14) & & 0.63 & & \\
\hline (15) & & & 0.62 & \\
\hline (17) & & 0.32 & & \\
\hline (19) & & 0.73 & & \\
\hline (20) & & & & -0.50 \\
\hline (22) & & & 0.40 & \\
\hline
\end{tabular}

*Original item numbers (Fenigstein et al., 1975).

\section{MAIN STUDY}

\section{Method}

The PrSC and the PbSC were subjected to construct validity analysis, in their revised forms and reliability analysis of each was repeated.

\section{Subjects}

The $S$ s were 253 students of M.E.T.U. drawn from various departments, 151 males and 101 females (1 $S$ did not mention his/her sex). The age range was $17-24 \mathrm{yr}$.

\section{Instruments}

Items 3, 7, 9 and 18 in the PrSC and item 21 in the PbSC, identificd as weak items in the second pilot study, were removed from the subscales. The order of the other items in the subscales (6 PrSC items and $6 \mathrm{PbSC}$ items) were not changed.

\section{RESULTS AND DISCUSSION}

$\alpha$ coefficients of the PrSC and PbSC were found to be 0.61 and 0.83 , respectively. The Pearson product-moment correlation between the two subscales was found to be 0.28 . The means of the PrSC and $\mathrm{PbSC}$ were obtained as $16.76(\mathrm{SD}= \pm 3.55)$ and $15.16(\mathrm{SD}= \pm 5.29)$ respectively.

From the factor analysis three factors emerged. All items had factor loadings above 0.30 on the related factor. The first factor having an Eigen value of 3.73 accounted for $31 \%$ of the variance, the second factor having an Eigen value of 1.82 accounted for $15.2 \%$ of the variance and the third factor having an Eigen value of 1.19 accounted for $9.9 \%$ of the variance. Factor 1 seemed to be defined by PbSC items, and Factor 2 and 3 seemed to be defined by PrSC items (see Table 1).

The two factor structure of the PrSC found by Bunkrant and Page (1984) and repeated by Piliavin and Charng (1988) was confirmed by the present study. Factor 2 seems to define 'self-reflectiveness' and factor 3 seems to define 'internal state awareness'. ['Self-reflectiveness' and 'internal state awareness', two different dispositional tendencies, have already been found to be associated with different attributional styles by Watson, Headrick and McKinney (1989).] Item loadings on the two factors were approximately similar to the former studies, except item 22 which exhibited a different pattern by loading on the 'self-reflectiveness' factor and items $3,7,9$ and 18 which were dropped out of this subscale. Therefore, the psychometric properties of the translated PrSC were consistent with the results of the reported studies.

$\mathrm{The} \mathrm{PbSC}$ appeared to be a functional instrument in respect to its reliability and construct validity. 
The factor structure of this subscale was consistent with the results reported in the original study

(Fenigstein et al., 1975), except item 21 which was already removed from the subscale.

It is thought that the Turkish version of the PrSC and PbSC can be used for further studies on Turkish populations, to explore the differential effect of 'self-reflectiveness', 'internal state awareness' and 'public self-consciousness' on different variables.

Acknowledgements - I would like to thank Jim Palmer and Sule Mann for proofreading of the article.

\section{REFERENCES}

Agatstein, F. C. \& Buchanan, D. B. (1984). Public and private self-consciousness and the recall of self relevant information. Personality and Social Psychology Bulletin, 10, 314-325.

Baldwin, M. W. \& Holmes, J. G. (1987). Salient private audiences and awareness of the self. Journal of Personality and Social Psychology, 52, 1087-1098.

Bunkrant, R. E. \& Page, T. J. (1984). A modification of the Fenigstein, Scheier, and Buss self-consciousness scale. Journal of Personality Assessment, 48, 629-637.

Carver, C. S. \& Scheier, M. F. (1981). Self-consciousness and reactance. Journal of Research in Personality, 15, 16-19.

Cheek, J. M. \& Briggs, S. R. (1982). Self-consciousness and aspects of identity. Journal of Research in Personality, I6, $401-408$

Davis, L. I. (1984). Judgment ambiguity, self-consciousness, and conformity in judgments of fashionability. Psychological Reports, 54, 671-675.

Duval, S. \& Wicklund, R. A. (1972). A theory of objective self-awareness. New York: Academic Press.

Duval, S. \& Wicklund, R. A. (1973). Effects of objective self-awareness on attribution of causality. Journal of Experimental Social Psychology, 9, 17-31.

Edelmann, R. J. (1985) Individual differences in embarrassment: Self-consciousness, self-monitoring and embarrassability. Personality and Individual Differences, 6, 223-230.

Fenigstein, A., Scheier, M. F. \& Buss, A. H. (1975). Public and private self-consciousness: Assessment and theory. Journal of Consulting and Clinical Psychology, 43, 522-527.

Franzoi, S. L. (1983). Self-concept differences as function of private self-consciousness and social anxiety. Journal of Research in Personality, 17, 275-287.

Franzoi, S. L. \& Brewer, L. C. (1984). The experience of self-awareness and its relation to level of self-consciousness: An experimental sampling study. Journal of Research in Personality, 18, 522-540.

Froming, W. J., Walker, G. R. \& Lopyan, K. J. (1982). Public and private self-awareness: When personal attitudes conflict with societal expectations. Journal of Experimental Social Psychology, 18, 476-587.

Ickes, W. J., Wicklund, R. A. \& Ferris, C. B. (1973). Objective self-awareness and self-esteem. Journal of Experimental Social Psychology, 9, 202-219.

Mueller, J. H., Thompson, W. B. \& Dugan, K. (1986). Trait distinctiveness and accessibility in the self-schema. Personality and Social Psychology Bulletin, 12, 81-89.

Nasby, W. (1985). Private self-consciousness, articulation of the self-schema and recognition memory of trait adjectives Journal of Personality and Social Psychology, 49, 704-709.

Nasby, W. (1989). Private and public self-consciousness and articulation of the self-schema. Journal of Personality and Social Psychology, 56, 117-123.

Penner, L. A. \& Wymer, W. E. (1983). The moderate variable approach to behavioral predictability: Some of the variables some of the time. Journal of Research in Personality, 17, 339-353.

Piliavin, J. A. \& Charng, H. (1988). What is the factorial structure of the private and public self-consciousness scales? Personality and Social Psychology Bulletin, 14, 587-595.

Scheier, M. F., Buss, A. H. \& Buss, D. M. (1978). Self-consciousness, self-report of aggressiveness, and aggression. Journal of Research in Personality, 12, 133-140.

Scheier, M. F. \& Carver, C. S. (1977). Self-focused attention and the experience of emotion: Attraction, repulsion, elation, and depression. Journal of Personality and Social Psychology, 35, 625-636.

Scheier, M. F. \& Carver, C. S. (1980). Private and public self-attention, resistance to change, and dissonance reduction. Journal of Personality and Social Psychology, 39, 390-405.

Scheier, M. F., Carver, C. S. \& Gibbons, F. X. (1979). Self-directed attention, awareness of bodily states, and suggestibility. Journal of Personality and Social Psychology, 37, 1576-1588.

Turner, R. G. (1978a). Consistency, self-consciousness, and the predictive validity of typical and maximal measures. Journal of Research in Personality, 12, 117-132.

Turner, R. G. (1978b). Effects of differential request procedures and self-consciousness on trait attributions. Journal of Research in Personality, 12, 431-438.

Turner, R. G., Gilliland, L. \& Klein, H. M. (1981). Self-consciousness, evaluation of physical characteristics, and physical attractiveness. Journal of Research in Personality, 15, 182-190.

Watson, P. J., Headrick, D. \& McKinney, J. (1989). Dimensions of Private self-consciousness and attributional style. Persunality and Individual Differences, 10, 367-369.

Wicklund, R. A. Objective self-awareness (1975). In Berkowitz, L. (Ed.), Advances in experimental social psychology, (Vol 8, pp. 233-275). New York: Academic Press. 